\title{
EVALUATION OF THE PEDAGOGICAL MODEL USED IN VIRTUAL REALITY SIMULATIONS FOR TRAINING PORTUGUESE FIREFIGHTERS
}

Vitor Reis, LE@D - Laboratório de Educação a Distância e eLearning, Portugal

\begin{abstract}
This paper details the pedagogical model used in virtual reality simulations for training Portuguese fire officers in emergency operations management and the evaluation of students about the implementation of the model throughout the training courses. The data of this quantitative study were collected over two years (2018-2019) and involved the participation of 89 fire officers from all over the country, who attended 12 training courses delivered at the Portuguese National Fire Service School (Escola Nacional de Bombeiros). Each course included seven to eight students, all experienced incident commanders with at least five years of service in the role. Every student played as incident commander in two different virtual reality training scenarios and their performance was assessed using a standardized evaluation tool. Students evaluated the pedagogical model implementation in virtual reality simulations through a questionnaire applied at the end of each course. The study's conclusions point out that most students consider the pedagogical model successfully implemented.
\end{abstract}

Keywords: Firefighters, training, virtual reality simulation, competencies, pedagogical model

\section{Introduction}

The current importance given to competencies challenges the training systems to introduce a change in teaching practices, resulting from the transfer of content-based learning to action-based learning. The training focused on developing competencies should involve simulation of problem situations specific to each professional activity, preparing students to act in the real context of work (Lima, 2005). To assess whether students have acquired the required level of competencies it is not enough to answer a written test, students must prove in practice what they know and can do through the application of knowledge in simulated or authentic work situations. 
Simulations can take many forms and be considered as a set of techniques and technologies, from verbal role play to virtual worlds (Keskitalo, 2015). Virtual reality simulation in firefighters' training allows experimental learning and complements more traditional learning strategies, including reading materials, case studies and live exercises with real fire (Launder, Lamb, Olde, \& Link, 2015). Simulations provide a learning opportunity that is both immersive and experiential (Aggarwal et al., 2010).

The use of virtual reality simulation in training tends to be dominated by the technological perspective, placing on a secondary level the pedagogical dimension that is intrinsic to any teaching and learning process. The training course used in this study follows the course' model developed by Reis (2018) for virtual reality simulation in the training of firefighters applying a pedagogical model established for health care education and adapted to this target audience.

This study aims to evaluate the students' perception of the implementation of the pedagogical model used in virtual reality simulations in a refresher training course for incident commanders.

This research is integrated in the Portuguese R \& D unit 4372/FCT Laboratory of Distance Education \& eLearning (LE@D), Universidade Aberta, financed by Foundation for Science and Technology.

\section{Virtual Reality Simulation}

Simulators based on virtual reality systems have been used to train professionals in different sectors of activity for decades, namely in the aeronautics (Blow, 2012), medicine (Ravert, 2002; Gomoll, Pappas, Forsythe, \& Warner, 2008), nursing (Hovancsek, 2007; Decker, Sportsman, Puetz, \& Billings, 2008) and in the military area (Christ, 2006). Several studies refer to the use of virtual reality simulation in the training of firefighters (Bliss, Tidwell, \& Guest, 1997; Hall, 2010; Bayouth, 2011; Gillespie, 2013) and research related to firefighters (Cohen-Hatton \& Honey, 2015).

In some European countries, simulations in virtual reality are used for the training and assessment of fire officers who perform incident command roles at the tactical and strategic levels of operations management. Simulations can be interrupted, controlled, repeated, and allow firefighters to prepare for situations that are not always possible to simulate under real conditions (Launder, Lamb, Olde, \& Link, 2015).

The main advantages of virtual reality simulation compared to live exercises are costeffectiveness, flexibility and the ability to create large-scale events. Virtual reality is less expensive because it requires less staff, less equipment and eliminates the need to create 
physical environments for training. It is flexible because trainers can easily build a huge variety of scenarios, choosing and combining the different environments and objects available in a library. But most importantly, the simulation software allows trainers to create events in a virtual environment that would be extremely difficult to recreate in a live exercise (Boosman, Lamb, \& Verhoef, 2015).

\section{Pedagogical Model}

Firefighters' training should be based on pedagogical practices appropriate to the high technical complexity and the strong practical element of rescue activities. The training focuses on learning motor tasks, handling and using equipment, performing manoeuvres and exercises, usually using simulation to recreate the conditions that firefighters must face in real emergency situations.

Keskitalo (2015) developed a pedagogical model for education using simulation, based on several studies carried out on virtual reality and simulation in health care (Keskitalo, 2011; 2012; Keskitalo, Ruokamo, \& Gaba, 2014). The pedagogical model is used for education of health professionals, using "task-trainer" models, high-fidelity mannequins and other medical simulators, including virtual reality simulators.

The model consists of six phases and defines for each phase the activities carried out by facilitators and students during the simulations:

38. Pre-activities - The tasks of the facilitators at this phase include designing the teaching process and the learning environment based on the specific objectives and characteristics of the students. The students' activities involve familiarization with the subject matter, including pre-study tasks, readings or theoretical classes.

39. Introduction - The facilitators present the course topic and the learning objectives. The simulation concept applied in the course is explained, including its advantages and disadvantages. In this phase, students should activate previous knowledge and experiences that serve as a basis for new knowledge. Previous knowledge can be activated through group discussion and sharing of experiences, construction of concept maps, among other activities.

40. Simulator and scenario briefing - This is the phase where the facilitators present the learning environment and the scenario. This phase should include a demonstration and practical exercises using the technology. The facilitators explain the objectives of the simulation exercise, the roles of the participants and the rules. At the end of this phase, students must be familiar with the virtual environment and understand what is expected of them so that they can assume their roles and get involved in the exercise. It is important they have learned to use the simulator. 
Reis, $V$.

Evaluation of the Pedagogical Model Used in Virtual Reality Simulations for Training Portuguese Firefighters

41. Scenarios - It is the main phase of the learning experience in which students participate in the simulation. At this stage it is important for the facilitators to explicitly indicate when the scenario starts and ends. The facilitators should promote an emotionally safe environment in which students are not afraid to expose their difficulties or lack of skills, so that they can be actively involved in the learning experience.

42. Debriefing - In the debriefing phase, the facilitators encourage students to carry out an analysis of the experience in order to improve their learning and future performance. Students should carry out an exercise of review and reflection on the learning process, the identification of their gaps in terms of knowledge, as well as the identification of new learning objectives. The facilitators should provide individualized feedback and emotional support to students. At this stage it is also important to compare the simulation exercise with the real world so that students can understand the differences and understand how the knowledge and skills they have acquired can be affected by the simulation.

43. Post-activities - In this phase the facilitators proceed to a critical evaluation of the teaching-learning process, considering the facilitation process and the students' activities. They must determine whether the learning objectives have been achieved in order to develop their skills as facilitators. From the students' perspective postactivities should correspond to the opportunity to test new knowledge and skills in a new setting or in the real world.

In the case of a course that includes more than one training scenario, some of the phases occur only once (pre-activities, introduction, simulator and scenario briefings and postactivities), while other phases (scenarios and debriefing) occur as many times as the number of scenarios performed (Keskitalo, 2015).

Although the pedagogical model was developed for the health area, it is flexible enough to be adapted and applied to other professional contexts in which the training processes integrate the use of simulations as a skill development tool, such as firefighters.

\section{Methodology}

The research was conducted at the Portuguese National Fire Service School (Escola Nacional de Bombeiros - ENB) and involved 89 fire officers from different fire brigades of all over the country who attended the refresher training courses for operational management in 2018 and 2019.

The data of this quantitative study were collected during 12 training courses taught at ENB in that period. Each training course included seven to eight students, all experienced 
Reis, $V$.

\section{Evaluation of the Pedagogical Model Used in Virtual Reality Simulations for Training Portuguese Firefighters}

incident commanders with at least five years of service in the role. There were no statistically significant differences between the groups of participants, in terms of age, qualifications, years of service and professional training.

The refresher training course aimed to develop and assess competencies related to situational awareness, decision making, plan, communication, command \& control and review. The course included a theoretical session and practical sessions based on simulation exercises, with formative and summative assessment.

The simulation exercises consisted of eight different virtual reality scenarios, from forest fires, urban and industrial fires, to accidents with multi-casualties and accidents involving hazardous materials. The scenarios created using the XVR software (Figure 1) were based on actual situations and the operational experience of the trainers' team, considering the learning objectives to be achieved and challenging learners to make critical decisions in complex situations. During exercises every student played as incident commander in two different training scenarios and their performance was assessed using Effective Command (Lamb, 2016).

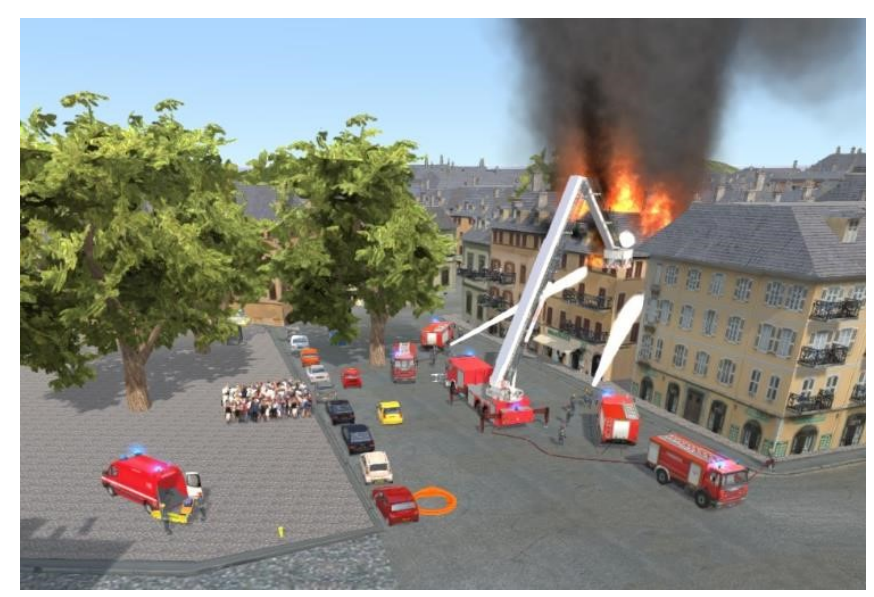

Figure 1. Virtual reality scenario of an urban fire

The Effective Command model referred by Lamb (2016) is an assessment tool designed specifically to assess command competencies in a training context. The methodology is based on the observation of competencies, called decision-making behaviours, which are demonstrated by participants in exercises developed in virtual reality simulation or real fire exercises. Decision-making behaviours focus on the specific competencies that are required for the role of Incident Commander (Lamb, Davies, Bowley, \& Williams, 2014). The application of this model is only completed after the debriefing conducted by the facilitator, where the participants reflect on the decisions taken and explain the reasoning behind their decisions, allowing the facilitator to carry out the assessment (Lamb, Davies, 
Reis, V.

\section{Evaluation of the Pedagogical Model Used in Virtual Reality Simulations for Training Portuguese Firefighters}

Bowley, \& Williams, 2014). The results of students' practical performance will not be considered in this paper.

The students' perceptions regarding the training course were collected through an evaluation questionnaire that was designed based on the studies by Hall (2010), Bayouth (2011), Gillespie (2013), and Keskitalo (2015). Students were asked to fill the questionnaire at the end of each course, which consisted of 5-point Likert-scale questions. For this paper were selected 12 questions of the questionnaire and quantitative data were studied through descriptive statistical analysis.

The researcher informed the participants about the study's background, objectives and requirements for confidentiality and anonymity. Informed consent was obtained to participate in the study.

\section{Results}

The students $(n=89)$ evaluated the implementation of the pedagogical model indicating their agreement with the statements about each of the phases of the model (Table 1).

Table 1: $\quad$ Students' evaluation regarding the implementation of the pedagogical model in virtual reality simulations

\begin{tabular}{|c|c|c|c|c|c|}
\hline Statements & $\begin{array}{l}\text { Strongly } \\
\text { Disagree }\end{array}$ & Disagree & $\begin{array}{c}\text { Neither Agree } \\
\text { nor Disagree }\end{array}$ & Agree & $\begin{array}{c}\text { Strongly } \\
\text { Agree }\end{array}$ \\
\hline \multicolumn{6}{|l|}{ Pre-activities } \\
\hline $\begin{array}{l}\text { Pre-course study materials provided to students } \\
\text { were adequate. }\end{array}$ & $0 \%$ & $2 \%$ & $6 \%$ & $69 \%$ & $24 \%$ \\
\hline Course objectives were clearly defined. & $0 \%$ & $0 \%$ & $0 \%$ & $47 \%$ & $53 \%$ \\
\hline \multicolumn{6}{|l|}{ Introduction } \\
\hline $\begin{array}{l}\text { Course objectives were communicated to } \\
\text { students. }\end{array}$ & $0 \%$ & $0 \%$ & $0 \%$ & $42 \%$ & $58 \%$ \\
\hline $\begin{array}{l}\text { Students' previous knowledge and experience } \\
\text { were considered during the course. }\end{array}$ & $0 \%$ & $0 \%$ & $6 \%$ & $67 \%$ & $26 \%$ \\
\hline \multicolumn{6}{|l|}{ Simulator and scenario briefing } \\
\hline $\begin{array}{l}\text { Adaptation to work with virtual reality simulator } \\
\text { was simple. }\end{array}$ & $1 \%$ & $0 \%$ & $0 \%$ & $51 \%$ & $48 \%$ \\
\hline $\begin{array}{l}\text { Support given by facilitators throughout the } \\
\text { simulations was individualized. }\end{array}$ & $1 \%$ & $4 \%$ & $3 \%$ & $45 \%$ & $46 \%$ \\
\hline \multicolumn{6}{|l|}{ Scenarios } \\
\hline Exercise scenarios were developed realistically. & $0 \%$ & $0 \%$ & $3 \%$ & $61 \%$ & $36 \%$ \\
\hline $\begin{array}{l}\text { Evolution of emergency situations during } \\
\text { exercises was realistic. }\end{array}$ & $1 \%$ & $4 \%$ & $6 \%$ & $58 \%$ & $30 \%$ \\
\hline \multicolumn{6}{|l|}{ Debriefing } \\
\hline $\begin{array}{l}\text { Critical reflection on performance was stimulated } \\
\text { by facilitators during debriefing. }\end{array}$ & $0 \%$ & $1 \%$ & $1 \%$ & $38 \%$ & $60 \%$ \\
\hline $\begin{array}{l}\text { Feedback provided by facilitators in debriefing } \\
\text { enabled the identification of improvements in } \\
\text { performance. }\end{array}$ & $0 \%$ & $0 \%$ & $0 \%$ & $36 \%$ & $64 \%$ \\
\hline \multicolumn{6}{|l|}{ Post-activities } \\
\hline $\begin{array}{l}\text { Training was aimed at solving problems related to } \\
\text { professional context. }\end{array}$ & $0 \%$ & $0 \%$ & $1 \%$ & $55 \%$ & $44 \%$ \\
\hline $\begin{array}{l}\text { Competencies acquired in training had practical } \\
\text { application in professional activities. }\end{array}$ & $0 \%$ & $0 \%$ & $0 \%$ & $45 \%$ & $55 \%$ \\
\hline
\end{tabular}


According to the results obtained in the statistical analysis, we can perceive that most of the students agreed or strongly agreed with the statements concerning each phase of the pedagogical model.

Most students strongly agreed with the statements about clear definition of course objectives (53\%), communication of course objectives to students (58\%), critical reflection on performance during debriefing (60\%), identification of improvements in performance enabled by facilitators feedback (64\%), and practical application in professional activities of competencies acquired in training (55\%).

Nevertheless, regarding the support given by facilitators throughout the simulation, $5 \%$ of the students disagree that the support was individualized, while $3 \%$ of the students do not agree or disagree with the statement. Concerning the evolution of emergency situations during exercises, $5 \%$ of the students disagree that the evolution was realistic, while $6 \%$ of the students do not agree or disagree with the statement. About pre-course study materials provided for students, $2 \%$ of the students disagree that the study materials were adequate, while $6 \%$ of the students do not agree or disagree with the statement.

\section{Conclusions}

The training of firefighters must follow recognized pedagogical models and practices for the preparation and development of practical exercises, construction of exercise scripts, creation of scenarios, conduct and evaluation of exercises and simulations.

The pedagogical model proposed by Keskitalo (2015) establishes an architecture to design, develop, conduct and evaluate simulations, defining a set of activities to be carried out by facilitators (trainers) and students in each phase, of which it is important to highlight the following guidelines:

- Learning objectives should be established and checked those during the learning process;

- Student's previous experiences should be the starting point for learning activities;

- Student's adaptation to the simulation system is essential before training begins;

- Individual differences in learning should be considered when possible;

- Scenarios should be based on real events and situations should evolve realistically;

- Students should work on simulations as they would in real life;

- Students should practice critical discussion and reflection about their performance;

- Students should receive individual guidance and feedback.

Considering that the implementation of the pedagogical model was evaluated by the students' agreement with the statements related to each phase, we can conclude that the 
vast majority consider the model successfully implemented throughout the virtual reality simulations.

\section{References}

Aggarwal, R., Mytton, O. T., Derbrew, M., Hananel, D., Heydenburg, M., Issenberg, B., Macaulay, C., Mancini, M., E., Morimoto, T., Soper, N., Ziv, A., \& Reznick, R. (2010). Training and simulation for patient safety. Retrieved from https://www.ncbi.nlm.nih.gov/pubmed/20693215

Bayouth, S. (2011). Examining firefighter decision making process and choice in virtual reality. Ph.D. Thesis. Iowa, USA: Iowa State University.

Bliss, J. P., Tidwell, P. D., \& Guest, M. A. (1997). The effectiveness of virtual reality for administering spatial navigation training to firefighters. Presence: Teleoperators and Virtual Environments, 6, 73-86.

Blow, C. (2012). Flight School in the Virtual Environment. Capabilities and Risks of Executing a Simulations-Based Flight Training Program. Retrieved from http://www.dtic.mil/dtic/tr/fulltext/u2/a567288.pdf

Boosman, M., Lamb, K., \& Verhoef, I. (2015). Why Simulation is Key for Maintaining Fire Incident Preparedness. Fire Protection Engineering, $2^{\text {nd }}$ Quarter, 46-56.

Christ, R. (2006). Preliminary Evaluation of a Novel Simulation-Based Tool for Training Rapid Decision-Making Skills (Research Report 1847). Arlington, VA: U.S. Army Research Institute for the Behavioral and Social Sciences.

Cohen-Hatton, S. R., \& Honey, R. C. (2015). Goal-Oriented Training Affects DecisionMaking Processes in Virtual and Simulated Fire and Rescue Environments. Journal of Experimental Psychology: Applied, 21(4), 395-406.

Decker, S., Sportsman, S., Puetz, L., \& Billings, L. (2008). The evolution of simulation and its contribution to competency. Journal of Continuing Education in Nursing, 39(2), 7480.

Gillespie, S. (2013). Fire Ground Decision-Making: Transferring Virtual Knowledge to the Physical Environment. Ph.D. Dissertation. Arizona, USA: Grand Canyon University.

Gomoll, A. H., Pappas, G., Forsythe, B., \& Warner, J. P. (2008). Individual skill progression on a virtual reality simulator for shoulder arthroscopy: a 3-year follow-up study. American Journal of Sports Medicine, 36(6), 1139-1142.

Hall, K. (2010). The effect of computer-based simulation training on fire ground incident commander decision making. Ph.D. Dissertation. Dallas, USA: University of Texas. 
Reis, $V$.

Evaluation of the Pedagogical Model Used in Virtual Reality Simulations for Training Portuguese Firefighters

Hovancsek M. (2007) Using simulation in nurse education. In Jeffries P.R. (Ed.). Simulation in Nursing Education; from Conceptualization to Evaluation (pp. 1-9). New York: National League for Nursing.

Keskitalo, T. (2011). Teachers' conceptions and their approaches to teaching in virtual reality and simulation-based learning environments. Teachers and Teaching: Theory and Practice, 17(1), 131-147.

Keskitalo, T. (2012). Students' expectations of the learning process in virtual reality and simulation-based learning environments. Australasian Journal of Educational Technology, 28(5), 841-856.

Keskitalo, T., Ruokamo, H., \& Gaba, D. (2014). Towards Meaningful Simulation-based Learning with Medical Students and Junior Physicians. Medical Teacher, 36(3), 230239.

Keskitalo, T. (2015). Developing a Pedagogical Model for Simulation-based Healthcare Education. Rovaniemi: Lapland University Press.

Lamb, K. (2016). How to be an effective incident commander. Fire \& Rescue, 102, 22-24.

Lamb, K., Davies, J., Bowley, R., \& Williams, J-P. (2014). Incident command training: the introspect model. International Journal of Emergency Services, 3(2), 131-143.

Launder, D., Lamb, K., Olde, J., \& Link, M. (2015). Simulating stimulation. Fire \& Rescue, 98, 32-34.

Lima, V. V. (2005). Competence: different approaches and implications in the training of healthcare professionals. Interface - Comunicação, Saúde, Educação, 9(17), 369-379.

Ravert, P. (2002). An integrative review of computer-based simulation in the education process. Computers Informatics Nursing, 20(5), 203-208.

Reis, V. (2018). Formação profissional de bombeiros portugueses: aplicação da simulação virtual ao desenvolvimento das competências de tomada de decisão (Doctoral dissertation). Portugal: Universidade Aberta. Retrieved from http://hdl.handle.net/10400.2/7444 